TAO, Vol.4, No.2, 155-170, June 1993.

\title{
The Calculation of Local Magnitude from the Simulated Wood-Anderson Seismograms of the Short-Period Seismograms in the Taiwan Area
}

TZAY-CHYN SHIN ${ }^{1}$

(Manuscript received 10 December 1992, in final form 24 April 1993)

\section{ABSTRACT}

The attenuation function, $\log A_{0}(\Delta)$, used in the calculation of local magnitude is derived for the Taiwan area. The simulated Wood-Anderson seismograms are constructed by using digital three-components short-period seismogram of the Central Weather Bureau Seismic Network, (CWBSN). The decay of peak amplitude with distance is the attenuation characteristic of seismic energy. Also, it essentially represents the distance correction term, $\log A_{\circ}(\Delta)$, after a proper normalization. Considering the focal depth of earthquakes in the Taiwan area, the $\log A_{0}(\Delta)$ functions are:

$$
\log A_{\circ}(\Delta)= \begin{cases}-0.00716 R-\log R-0.39 & (0 \mathrm{~km}<\Delta \leq 80 \mathrm{~km}) \\ -0.00261 R-0.83 \log R-1.07 & (80 \mathrm{~km}<\Delta)\end{cases}
$$

for shallow earthquakes (focal depth, $h \leq 35 \mathrm{~km}$ ) and

$$
\log A_{\circ}(\Delta)=-0.00326 R-0.83 \log R-1.01
$$

for deep earthquakes $(h>35 \mathrm{~km})$

where $\Delta$ is epicentral distance, $R\left(=\sqrt{\Delta^{2}+h^{2}}\right)$ is the hypocentral distance. Results also show that the local magnitude of a deep earthquake is underestimated by using the Richter's $\log A_{0}(\Delta)$ values $(1935,1958)$ with comparison to the $M_{L}$ value obtained from the revised $\log A_{0}(\Delta)$ values of this study. By applying the revised attenuation function, a compatible local magnitude can be calculated from the strong motion data.

The conversion of duration magnitude, $M_{D}$ which is currently used in the Taiwan area, to $M_{L}$ is in the form:

$$
M_{L}=1.12 M_{D}+0.03 \pm 0.21
$$

\footnotetext{
1 Central Weather Bureau, 64, Kung Yuan Road, Taipei, Taiwan, R.O.C.
} 


\section{INTRODUCTION}

The local magnitude, $M_{L}$, popularly used by local seismic network was formulated by Richter $(1935,1958)$ as :

$$
M_{\mathrm{L}}=\log A-\log A_{\mathrm{o}}(\Delta)
$$

where $A$ is the maximum amplitude in millimeters recorded on the standard Wood-Anderson torsion seismograph with static magnification of 2800, natural period of 0.8 second, and damping factor of 0.8 at an epicentral distance $\Delta, A_{\circ}$ which describes the loss of energy with respect to distance such as geometrical spreading, anelastic attenuation, and wave scattering is distant dependent. These effects depend on the characteristics of the crust and upper mantle of applied area. The $\log A_{\diamond}$ function is of more interesting in engineering seismology and seismology.

The $M_{L}$ formulation was originally designed for the region of southern California where the function of $\log A_{0}(\Delta)$ was empirically determined. However, equation (1) is also used in the other seismic network to determined local magnitude as the Richter's southern Califomia $\log A_{\circ}$ is used with the assumption of similar characteristics of the crust and upper mantle. On the other hand, a number of studies (Yeh et al, 1982; Bakun and Joyner, 1984; Chavoz and Priestley, 1985), reconstructed the $\log A_{\diamond}$ function for the applied area by using synthetic Wood-Anderson seismogram from strong motion or short period seismogram.

In this paper, I use short period digital seismograms to simulate Wood-Anderson seismograms. To study the attenuation of seismic wave, a new $\log A_{0}(\Delta)$ curve can be developed for Taiwan area and calibrated so that $\log A_{\circ}(100)=-3$. The variety of $\log A_{\circ}(\Delta)$ for earthquake occurring at different focal depths is taken into account. It is due to the wide range of focal depths in Taiwan area. This gives less Lg wave excitation (Campillo et al. 1983) for earthquake occurring beneath the crust.

\section{DATA}

Since 1991, the Central Weather Bureau (CWB) has upgraded the seismic network, named as Central Weather Bureau Seismic Network (CWBSN). The local station of new system is installed with a three-component short-period digital seismographs while a realtime operation is performed in the center. The seismograph is the velocity type sensor, S13, and has adjustable natural frequency of from $0.75 \mathrm{~Hz}$ to $1.1 \mathrm{~Hz}$. The signal is digitized locally by a 12-bit ADD converter with 100 samples per second, and then transmitted through the dedicated phone line of 4800 baud rate. The network consists of 68 stations, including 43 digital stations belonging to the CWB and 25 one-component short-period stations of the Taiwan Telemetered Seismograph Network (TTSN), which is operated by the Institute of Earth Sciences (IES), Academia Sinica since 1973. The telemetry of TTSN is analog transmission. The signal is digitized with the same sample rate as CWB's signal at the center of CWBSN. The system is well calibrated by using weight lift and $1 \mathrm{~Hz}$ harmonic current feed technique. The normalized instrument responses for three instrumental type are shown in Figure 1. The sensitivity factor as well as station parameters are listed in Table 1. The last column of Table 1 is the instrumental type : 1 for S-13 sensor with analog transmission; 2 for $\mathrm{L}-4 \mathrm{C}$ sensor with analog transmission; 3 for $\mathrm{S}-13$ sensor with digital transmission whose response curves are shown in Figure 1. 
Fig. 1. Nomalized instrument responses. The number written near by curve denotes the instrument type as listed. in the last column of Table 1 .

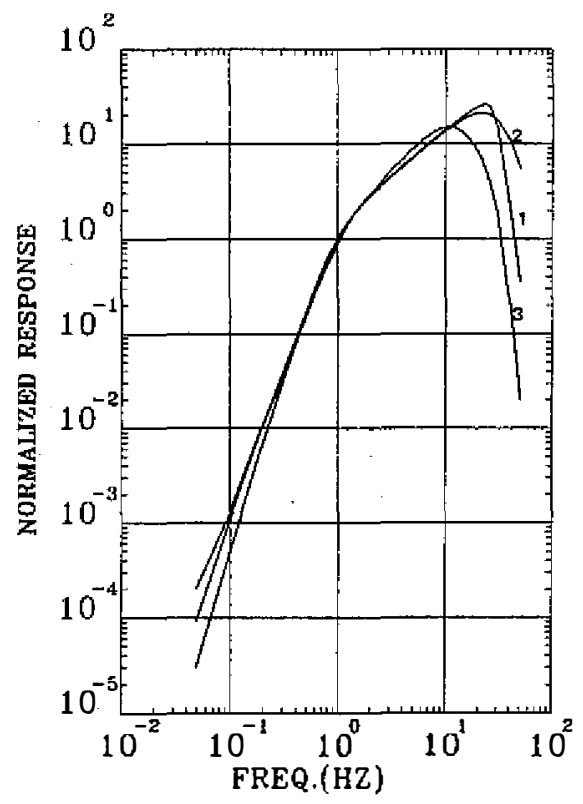

At each of the 43 digital stations, a strong motion accelerograph, A800 (Teledyne), is also installed. The instrument is a triggered type and the triggered level is generally set up at $2 \%$ of the full scale $(1 \mathrm{~g})$. The local accelerograph is connected to dial-up phone line for data retrieval, calibration, and timing synchronization.

The current local magnitude is calculated from the simulated Wood-Anderson seismogram from the short-period digital seismogram while the Richter's $\log A_{\mathrm{o}}(\Delta)$ curve $(1935$, 1958 ) is used. The uncertainty of local magnitude may be caused by the use of $\log A_{0}(\Delta)$ which is essentially valid for southern Califomia. Moreover, the Richter's $\log A_{\circ}(\Delta)$ function $(1935,1958)$ is of depth-independence since almost all earthquakes in southem California are shallow. But, it is not so for earthquakes in Taiwan.

In order to derive a proper $\log A_{\mathrm{o}}(\Delta)$ function which is suitable for the Taiwan area, the ray path of selected earthquakes should be able to sample the whole area. Totally, 224 earthquakes occurring in the period of Sept. 1991 to Feb. 1992 with wide range of focal depth from shallow to $120 \mathrm{~km}$ are selected in this study on the basis of the following criteria : (1) The event was recorded by at least 10 digital stations, without clipped amplitude (2048 counts) on horizontal components; and (2) The distance from the nearest station to the farthest one under condition (1) must be greater than $150 \mathrm{~km}$. Figure 2 is a location map to show all events used in this study.

\section{DATA ANALYSIS AND RESULTS}

The value of the amplitude of seismic wave at epicentral distance $\Delta$, denoted as $A(\Delta)$, it is the combined results of material attenuation and geometrical spreading. The $A(\Delta)$ can be written as

$$
A(\Delta)=C e^{-\gamma R} / R^{n} S
$$


Table 1. The stations parameters of CWBSN.

\begin{tabular}{|c|c|c|c|c|}
\hline $\begin{array}{l}\text { station } \\
\text { Code }\end{array}$ & $\begin{array}{l}\text { Latitude } \\
\text { Degree }\end{array}$ & $\begin{array}{l}\text { Longitude } \\
\text { Degree }\end{array}$ & $\begin{array}{c}\text { Gain } \\
\text { (count/mu) }\end{array}$ & $\begin{array}{c}\text { Instrument } \\
\text { Type* }\end{array}$ \\
\hline TAP & 25.04 & 121.52 & .013 & 3 \\
\hline HSN & 24.80 & 120.97 & .013 & 3 \\
\hline TCU & 24.15 & 120.68 & .044 & 3 \\
\hline CHY & 23.50 & 120.42 & .044 & 3 \\
\hline ALS & 23.51 & 120.81 & .208 & 3 \\
\hline TAI & 23.00 & 120.20 & .013 & 3 \\
\hline PNG & 23.57 & 119.56 & .013 & 3 \\
\hline KAU & 22.57 & 120.31 & .022 & 3 \\
\hline HEN & 22.01 & 120.74 & .089 & 3 \\
\hline ILA & 24.77 & 121.75 & .013 & 3 \\
\hline HWA & 23.98 & 121.61 & .013 & 3 \\
\hline CHK & 23.10 & 121.37 & .013 & 3 \\
\hline TTN & 22.75 & 121.15 & .013 & 3 \\
\hline TAW & 22.36 & 120.90 & .013 & 3 \\
\hline LAY & 22.04 & 121.55 & .013 & 3 \\
\hline NCU & 24.97 & 121.19 & .013 & 3 \\
\hline YUS & 23.48 & 120.95 & .208 & 3 \\
\hline PCY & 25.63 & 122.07 & .013 & 3 \\
\hline SML & 23.88 & 120.90 & .026 & 3 \\
\hline NST & 24.63 & 121.00 & .013 & 3 \\
\hline WSF & 23.64 & 120.22 & .013 & 3 \\
\hline WTC & 23.86 & 120.28 & .013 & 3 \\
\hline SCL & 23.18 & 120.19 & .026 & 3 \\
\hline SGS & 23.08 & 120.58 & .104 & 3 \\
\hline SGL & 22.73 & 120.49 & .052 & 3 \\
\hline ENA & 24.43 & 121.74 & .013 & 3 \\
\hline ESL & 23.81 & 121.43 & .104 & 3 \\
\hline ENT & 24.64 & 121.57 & .052 & 3 \\
\hline NSY & 24.42 & 120.76 & .013 & 3 \\
\hline EHY & 23.51 & 121.32 & .013 & 3 \\
\hline WNT & 23.88 & 120.68 & .013 & 3 \\
\hline WGK & 23.69 & 120.56 & .013 & 3 \\
\hline WTP & 23.25 & 120.61 & .026 & 3 \\
\hline STY & 23.16 & 120.76 & .052 & 3 \\
\hline EGS & 24.84 & 121.93 & .013 & 3 \\
\hline NSK & 24.68 & 121.36 & .013 & 3 \\
\hline SSD & 22.75 & 120.63 & .013 & 3 \\
\hline EHC & 24.27 & 121.73 & .013 & 3 \\
\hline WDT & 23.76 & 121.13 & .013 & 3 \\
\hline SCZ & 22.37 & 120.62 & .013 & 3 \\
\hline TAII & 23.01 & 120.13 & .022 & 3 \\
\hline TAPI & 25.04 & 121.52 & .800 & 3 \\
\hline TWA & 24.98 & 121.58 & .740 & 1 \\
\hline TWB1 & 25.01 & 121.99 & .790 & 1 \\
\hline TWC & 24.61 & 121.85 & .780 & 1 \\
\hline TWD & 24.08 & 121.60 & .380 & 1 \\
\hline TWE & 24.72 & 121.67 & .960 & 1 \\
\hline TWF1 & 23.35 & 121.30 & .740 & 1 \\
\hline TWG & 22.82 & 121.07 & .740 & 1 \\
\hline TWH & 22.68 & 121.48 & .480 & 2 \\
\hline TWI & 22.07 & 121.50 & .230 & 2 \\
\hline TWJ1 & 22.37 & 120.88 & .230 & 2 \\
\hline TWK1 & 21.94 & 120.81 & .470 & 1 \\
\hline
\end{tabular}


Table 1. (Continued)

\begin{tabular}{lcccc}
\hline $\begin{array}{c}\text { Station } \\
\text { Code }\end{array}$ & $\begin{array}{c}\text { Latitude } \\
\text { Degree }\end{array}$ & $\begin{array}{c}\text { Longitude } \\
\text { Degree }\end{array}$ & $\begin{array}{c}\text { Gain } \\
\text { (count/mu) }\end{array}$ & $\begin{array}{c}\text { Instrument } \\
\text { Type* }\end{array}$ \\
\hline TWL & 23.27 & 120.49 & .370 & 1 \\
TWM1 & 22.82 & 120.42 & .490 & 2 \\
TWO1 & 23.57 & 120.59 & .910 & 2 \\
TWP & 22.35 & 120.36 & .230 & 2 \\
TWQ & 24.27 & 120.84 & .550 & 1 \\
TWQ1 & 24.35 & 120.77 & .230 & 1 \\
TWR & 24.64 & 121.08 & .770 & 1 \\
TWS1 & 25.10 & 121.42 & .220 & 1 \\
TWT & 24.25 & 121.18 & .740 & 1 \\
TWU & 24.88 & 121.53 & .380 & 1 \\
TWX & 25.20 & 121.66 & .450 & 1 \\
TWY & 25.28 & 121.60 & .250 & 1 \\
TWZ & 25.10 & 121.58 & .220 & 1 \\
TYC & 23.90 & 120.86 & .740 & \\
\hline
\end{tabular}

* 1 - Analog transmission station of $s-13$ sensor.

2 - Analog transmission station of L-4C sensor.

3 - Digital transmission station of $s-13$ sensor.

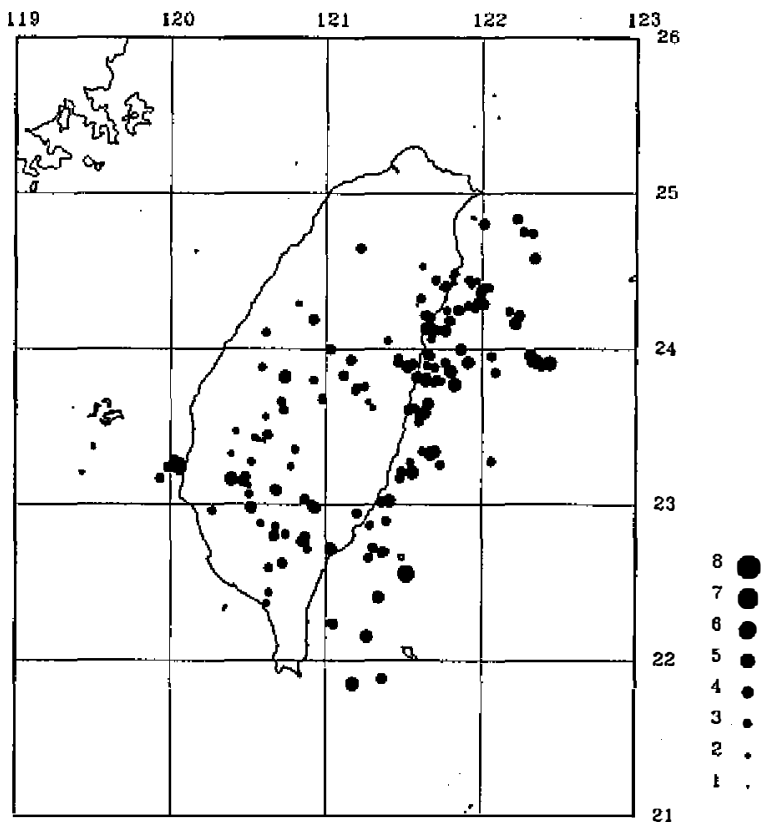

Fig. 2. The location map of 224 events used in this study. The size of solid circle represents the magnitude of earthquake. 
where $\gamma$ and $n$ are the attenuation and geometrical spreading coefficients respectively; $R=\sqrt{\Delta^{2}+h^{2}}$ ( $h$ is focal depth); $C$ is a constant; and $S$ is a site-dependent constant, which is affected by site effects and varies with station's magnification. Equation (2) can be related to the function $A_{0}(\Delta)$ shown in equation (1) as long as $A(\Delta)=1 \mathrm{~mm}$ at $\Delta=100$ km.

The synthetic Wood-Anderson seismogram (SWAS) can be constructed from the shortperiod seismogram. The processing is explained as follows. First, the short-period seismogram is transformed into frequency domain; Second, the instrument response is removed to have ground displacement spectrum; then multiplied by a Wood-Anderson instrument response in frequency domain; Finally, the spectrum is transformed back into the time domain. It gives a SWAS (Bakun et al., 1978). Figure 3 shows the examples of original short-period seismograms and SWAS. I measured three different types of zero-peak amplitude: (1) The maximum value from vertical component denoted as $Z$, and (2) The maximum value of the square-root of the vectorial sum of the peak amplitudes in the NS and EW components denoted as $H 1=\sqrt{H N^{2}(M a x)+H E^{2}(M a x)}$, and (3) The maximum value of the vectorized horizontal components denoted as $H 2=\sqrt{H N^{2}+H E^{2}}$ । Max.

To fit all measured peak amplitudes of SWAS $(Z, H 1$, or $H 2)$ into equation (2) individually, I adopt the multiple linear regression analysis method by taking logarithm on both sides of equation (2) as

$$
\log A(\Delta) R^{n}=\log C-\gamma R \log e+\log S
$$

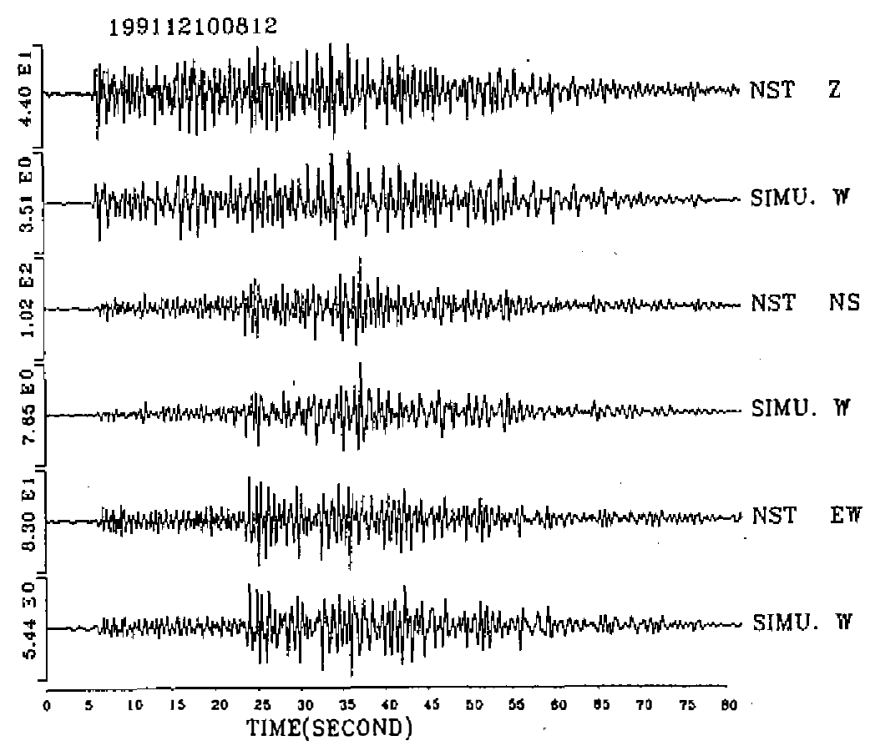

Fig. 3. Examples of simulated Wood-Anderson seismogram from short-period seismogram. The SWAS is plotted next to short-period seismogram. 
The reduced amplitude in the left hand side of equation (3) has linear relationship with hypocentral distance $R$. In order to resolve $C$ and $S$ terms which both are constants representing different physical meanings, I applied an iteration technique. The term $S$ is initialized as unit. The $S$ tern of each station is calculated by taking the averaged ratio of the observed value to the theoretical value after first iteration. Then, it can be used for the next iteration of regression analysis. The processing will be stopped by checking the ratio values as they approach 1 or the multiplication of all averaged ratio values approaching 1 . Usually, it takes 3 or 4 iterations to make one of two conditions satisfied. The function $A_{\circ}(\Delta)$ is then formed by adjusting $C$ to fit the scale used by Richter's $(1935,1958)$.

Assurning $n=0.833$ for the $L g$ wave propagation, Figure 4 shows the data points of reduced amplitude versus distance after 3 iterations of regression analysis. It is worth noting that a single linear equation can not fit the data points, especially at the short distance $(\Delta \leq 80 \mathrm{~km})$. The result indicates that the dominant wave is changed at different distance ranges. It is believed that shear wave has large amplitude at short distance while $L g$ wave is conspicuous at regional distance. It is consistent with the other observations (Bouchon, 1982; Hasegawa, 1983; Dwyer et al., 1983; Campillo et al, 1984; Shin and Hermann, 1987). Considering this result and the depth distribution of earthquakes in the Taiwan area, the regression analysis is performed by three cases (1) Shallow earthquakes $(h \leq 35 \mathrm{~km})$ and long distance range $(\Delta>80 \mathrm{~km}) ;(2)$ shallow earthquakes $(h \leq 35 \mathrm{~km})$ and short distance range $(\Delta \leq 80 \mathrm{~km})$; and (3) deep earthquakes $(h>35 \mathrm{~km})$

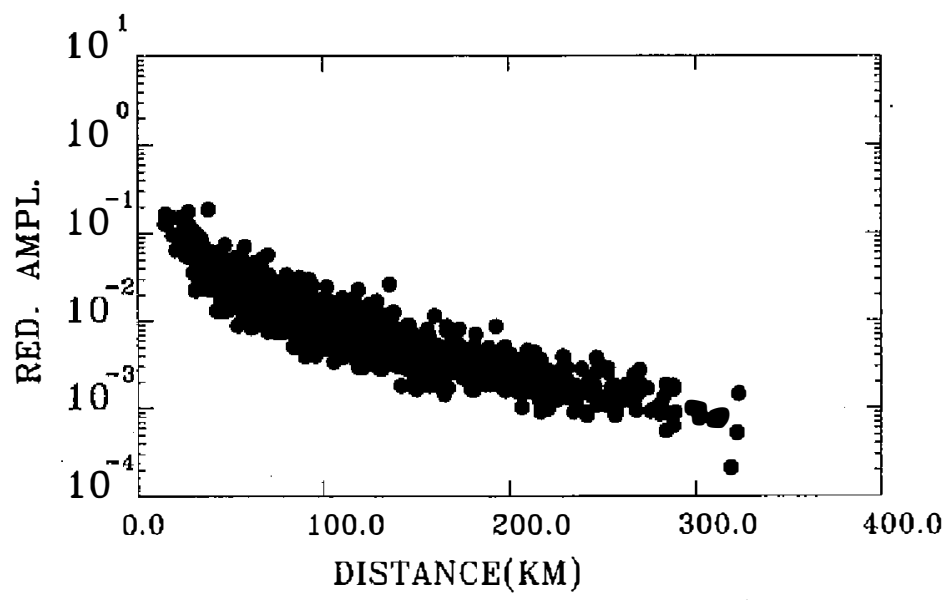

Fig. 4. Reduced amplitude vs distance for 224 earthquakes. It is obvious that a single linear line can not fit the data points.

\subsection{Case 1}

Totally, 102 earthquakes are used in this case. Each event has at least 10 recordings in the required distance range which is greater than $150 \mathrm{~km}$. Using $n=0.833$ and $H 1$ to perforn regression analysis, Figure 5 displays the data points of reduced amplitude vs. distance before (as open circles) and after (as solid circles) regression analysis. The linearity is more 


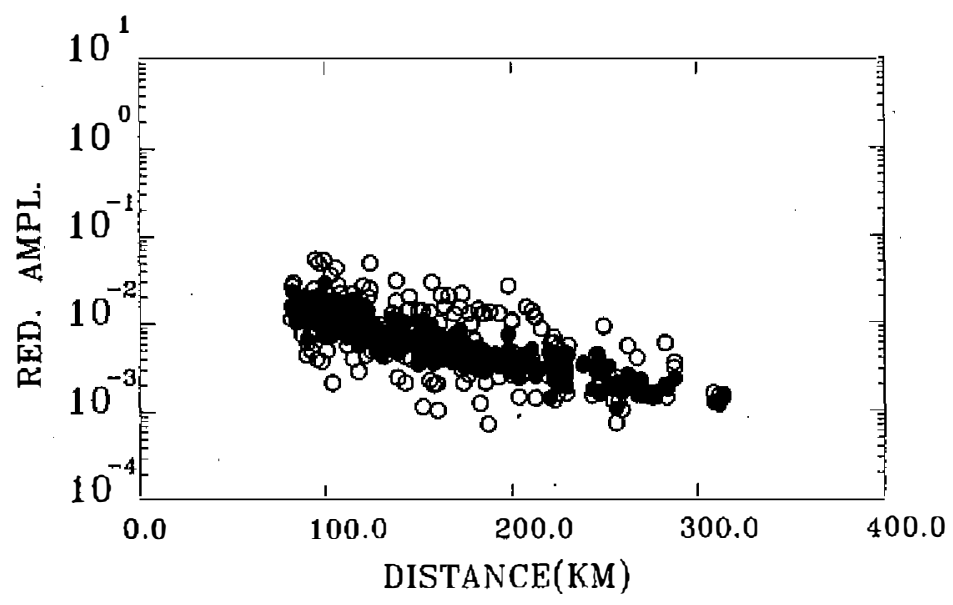

Fig. 5. The reduced amplitude of $H 1$ for shallow earthquake in long distance range. Open circles represent the data points after one iteration of regression analysis: solid circles are the results of three iteration. The slope of solid circles on semi-log scale is 0.0026 which is equal to $\gamma=0.0061$ $\mathbf{k m}^{-1}$.

remarkable as regression is applied. The slope of 0.00261 is essentially implying the attenuation effects of the area. Therefore, the slope can be converted to have $\gamma=0.0061 \mathrm{~km}^{-1}$. To realize the variation of $\gamma$ caused by using different kinds of peak amplitude, the data of $H 2$ and $Z$ are also taken for regression analysis. Figure 6 shows the distribution of reduced amplitude of $H 2$ (as open circles) and $Z$ (as solid triangles) individually.

The $\gamma$ values of $0.006 \mathrm{~km}^{-1}$ and $0.0059 \mathrm{~km}^{-1}$ are obtained respectively. The same $\gamma$ value tells that the propagation of seismic wave is similarly attenuated on the horizontal and vertical components. Results show that the $\log A_{\circ}(\Delta)$ function can be expressed as $-0.00261 \mathrm{R}-0.83 \log \mathrm{R}-1.07$.

\subsection{Case 2}

Using recordings within short distance range, at least 4 recordings are required and the distance range greater than $50 \mathrm{~km}$. There are 84 earthquakes meeting the requirement. Assuming $n=1.0$ of body wave propagation and $H 1$ used, Figure 7 is the distribution of reduced amplitude with respect to the distance before (open circles) and after (solid circles) regression analysis respectively. The slope of 0.00716 is equal to $\gamma=0.0165 \mathrm{~km}^{-1}$. The same values are obtained as using either $H 2$ or $Z$ peak amplitude. Using the $\gamma$ value, $\log A_{\mathrm{o}}(\Delta)$ is in the form of $-0.00716 \mathrm{R}-\log \mathrm{R}-0.38$ in this case.

\subsection{Case 3}

There are 53 deep earthquakes $(h>35 \mathrm{~km})$ which are taken into account. For each of them, there are at least 10 recordings in the distance range greater than $150 \mathrm{~km}$. Using $n=0.833$ and $H 1$, Figure 8 is the reduced amplitude distribution before (open circles) and 


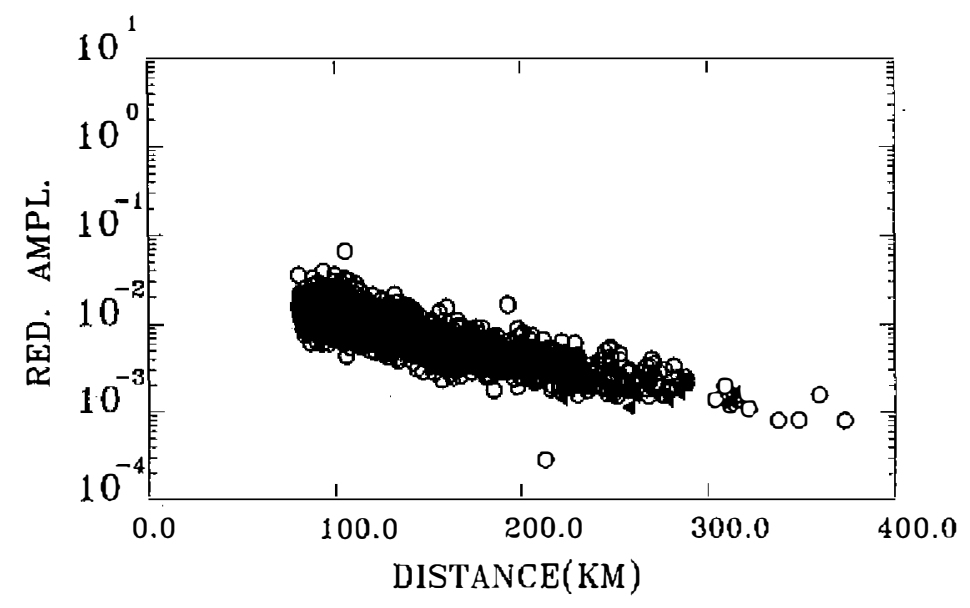

Fig. 6. The reduced amplitude distribution of $H 2$ (open circles) and $Z$ (solid triangles) in long distance range. The $\gamma$ values of $0.006 \mathrm{~km}^{-1}$ and 0.0059 $\mathrm{km}^{-1}$ are obtained respectively. The similar value of $\gamma$ from $H 1, H 2$, and $Z$ indicates the same average path effects of seismic wave at all components for Taiwan area.

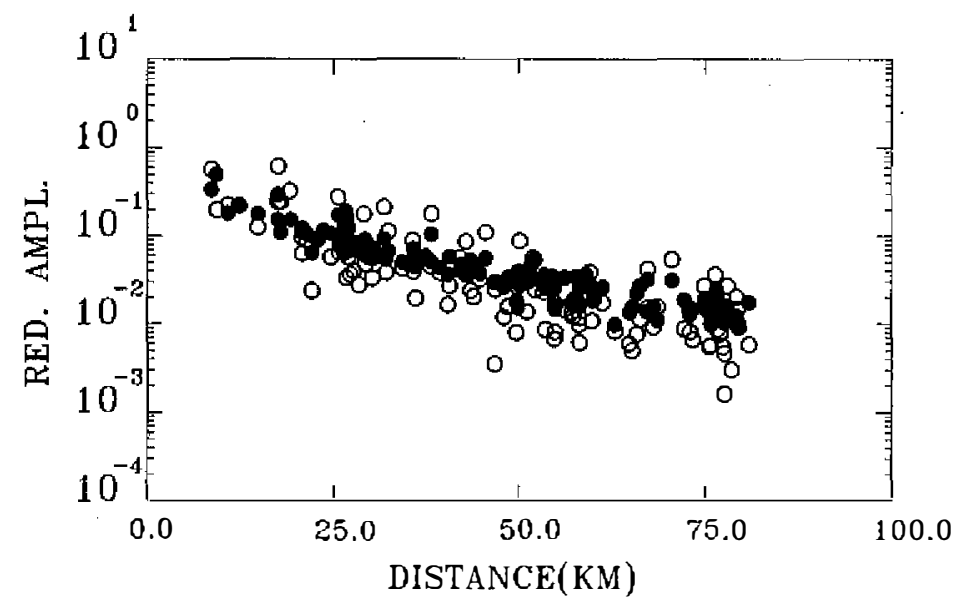

Fig. 7. The same notation as Figure 5 while $H 1$ selected in short distance. The slope of solid circles is 0.00716 equating to $\gamma=0.0165 \mathrm{~km}^{-1}$. 


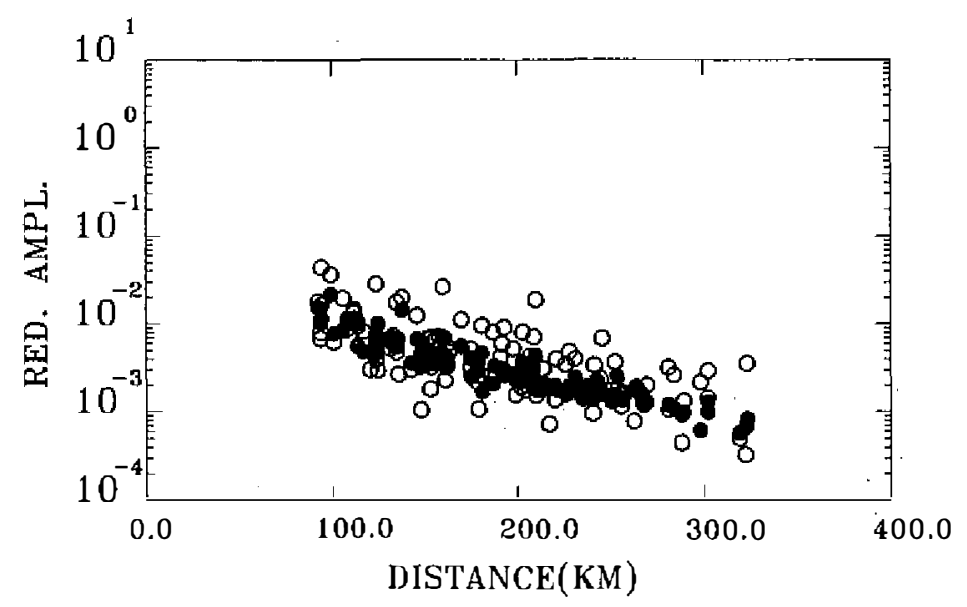

Fig. 8. The distribution of reduced amplitude. The $H 1$ data of deep earthquakes are used, and the notations are the same as Figure 5. The slope of 0.00326 equals to $\gamma=0.0075 \mathrm{~km}^{-1}$.

after (solid circles) regression analysis respectively. The slope in the Figure 8 of solid circles is 0.00326 and equals to $\gamma=0.0075 \mathrm{~km}^{-1}$. Therefore, the $\log A_{\mathrm{o}}(\Delta)$ function can be expressed by $-0.00326 \mathrm{R}-0.83 \log \mathrm{R}-1.01$.

\section{DISCUSSION AND CONCLUSIONS}

Applying the multiple regression analysis for SWAS, a revised distance correction term for local magnitude is derived. The new $\log A_{\mathrm{o}}(\Delta)$ function can be expressed as followings:

$$
\log A_{\circ}(\Delta)= \begin{cases}-0.00716 R-\log R-0.39 & (0 \mathrm{~km}<\Delta \leq 80 \mathrm{~km}) \\ -0.00261 R-0.83 \log R-1.07 & (80 \mathrm{~km}<\Delta)\end{cases}
$$

for shallow earthquakes ( $h \leq 35 \mathrm{~km}$ ), and

$$
\log A_{\circ}(\Delta)=-0.00326 R-0.83 \log R-1.01
$$

for deep earthquakes $(h>35 \mathrm{~km})$

Figure 9 shows the comparison of $\log A_{0}(\Delta)$ curves. The circles represent the Richter's curve for southern California. The squares are the attenuation function obtained by Yeh $e t$ al (1982) by SWAS of strong motion data of Taiwan area. The line is obtained in this study of assuming focal depth at $10 \mathrm{~km}$ representing the attenuation curve of shallow earthquakes. The results indicate that the attenuation of seismic waves at short distance in Taiwan area is greater than those in southern Califomia, but slightly less at long distance. The result from Yeh et al. (1982) is only for reference since the selected strong motion data are too few to 


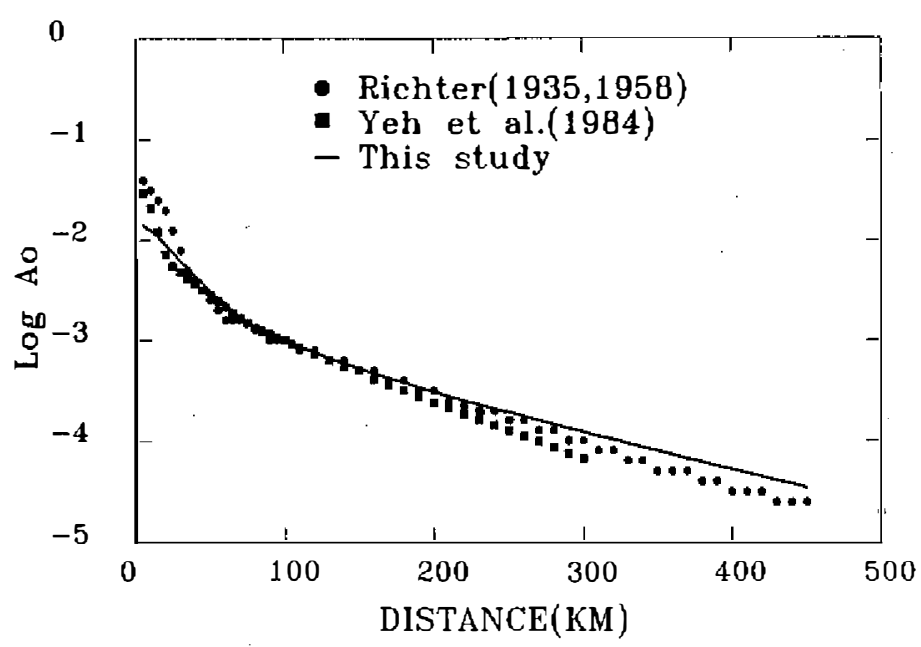

Fig. 9. Comparison of $\log A_{\mathrm{o}}(\Delta)$ curves. The solid circles are from Richter $(1935,1958)$. The squares are the results of Yeh et af. (1984). The solid line is from this study assuming $h=10 \mathrm{~km}$.

sample the whole area. Therefore, their attenuation curves cannot represent the full characteristics of the Taiwan area.

The attenuation coefficient $(\gamma)$ can be related to the sesimic quality factor, $Q$, if the form $Q=\pi f / \gamma U$, where $f$ is the frequency of the wave, and $U$ is its velocity. Thus, the $\gamma$ value obtained from case 1 can be used to estimate the $Q$ for $L g$ in the Taiwan area. The $L g-Q$ is about 190 by assuming $U=3.5 \mathrm{~km} / \mathrm{sec}$ and $f=1.25 \mathrm{~Hz}$ (the natural frequency of Wood-Anderson seismograph). Similarly, the shear wave $Q$ of 165 can be calculated by assuming the shear velocity of $3.3 \mathrm{~km} / \mathrm{sec}$. All these results are consistent with the average $Q$ values obtained by previous works for the Taiwan area (Chang and Yeh, 1983; Wang, 1988; Wang and Liu, 1990; Shin et al. 1987).

Using the $\log A_{\mathrm{o}}(\Delta)$ curve developed in this study, the local magnitudes are recomputed by using $H 1$ denoted as $M_{L}(H 1), H 2$ as $M_{L}(H 2), Z$ as $M_{L}(Z)$ of SWAS for 224 earthquakes. Figures 10a and 10b show the comparison of $M_{L}(H 1)$ versus $M_{L}(H 2)$ and $M_{L}(H 1)$ versus $M_{L}(Z)$ respectively. It appears that the same magnitude values are obtained no matter the $H 1$ or $H 2$ used. On the other hand, the local magnitude calculated from $Z$ is smaller than those from $H 1$ or $H 2$ by a factor of 0.5 magnitude unit. It turns out that the average ratio of horizontal peak amplitude to vertical peak amplitude is approximately 3.

The difference of local magnitude calculation by applying the Richter's $\log A_{\mathrm{o}}(\Delta)$ $\left(M_{L}(\right.$ old $\left.)\right)$ and the $\log A_{\mathrm{o}}(\Delta)$ of this study $\left(M_{L}\right.$ (new)) is shown as open circles in Figure 11. The data points include all events occurring in the Taiwan area from Sep. 1991 to Feb. 1992 and can be fitted by the regression line of

$$
M_{L}(\text { new })=0.97 M_{L}(\text { old })+0.12
$$


(a)

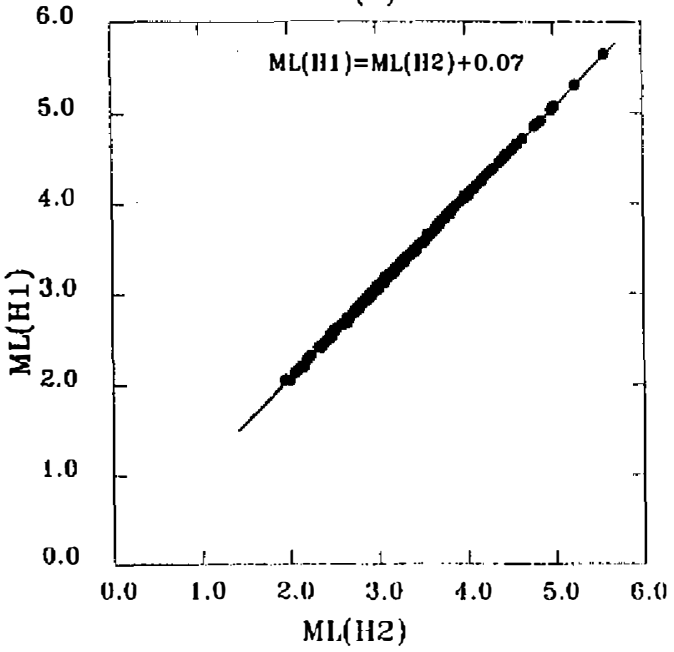

(b)

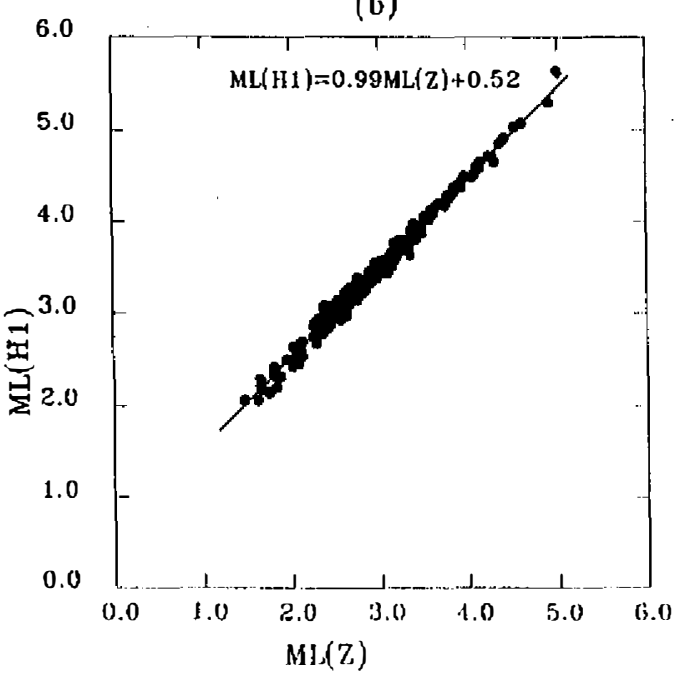

Fig. 10. (a) $M_{L}(H 1)$ vs $M_{L}(H 2)$, (b) $M_{L}(H 1)$ vs $M_{L}(Z)$. The linear relationships are written in figure respectively.

Some data points deviate from this line and showing a underestimation of magnitude by using Richter's $\log A_{0}(\Delta)$. Taking the shallow earthquakes only (solid circles), they display a good linear trend as $M_{L}$ (new) $=0.97 M_{L}$ (old) +0.09 . It indicates that the data points which deviate from the main trend of data points in Figure 11 are mostly for deep earthquakes.

Since 1973, the duration of earthquake signals recorded on seismogram has been used by the TTSN to determine magnitude $\left(M_{D}\right)$ in the form

$$
M_{D}=-0.87+2.00 \log D+0.0035 \Delta
$$

obtained by Lee et al, (1972) from southern Califomia earthquakes, where $D$ is total duration time in second. The $M_{D}$ for the Taiwan earthquakes can be related to $M_{L}$ in the form (Yeh and Hsu, 1985):

$$
M_{L}=0.94 M_{D}+1.04 \pm 0.28
$$

It is noted that $M_{L}$ in equation (6) was determined from the $\log A_{\circ}(\Delta)$ values obtained by Yeh et al. (1982). In order to establish a unique magnitude scale, it is necessary to compare the $M_{D}$ with the $M_{L}$ of this study. Using the same data set, there are 221 earthquakes whose duration magnitudes were determined by the TTSN. Figure 12 shows the data points of $M_{L}$ vs $M_{D}$. The relationship is in the form

$$
M_{L}=1.12 M_{D}+0.03 \pm 0.21
$$

and shown by a solid line in the figure. The dashed line is from equation (6). Obviously, equation (6) gives an overestimated $M_{L}$ values comparing to equation (7), especially for the magnitude of earthquakes smaller than 5.6. 


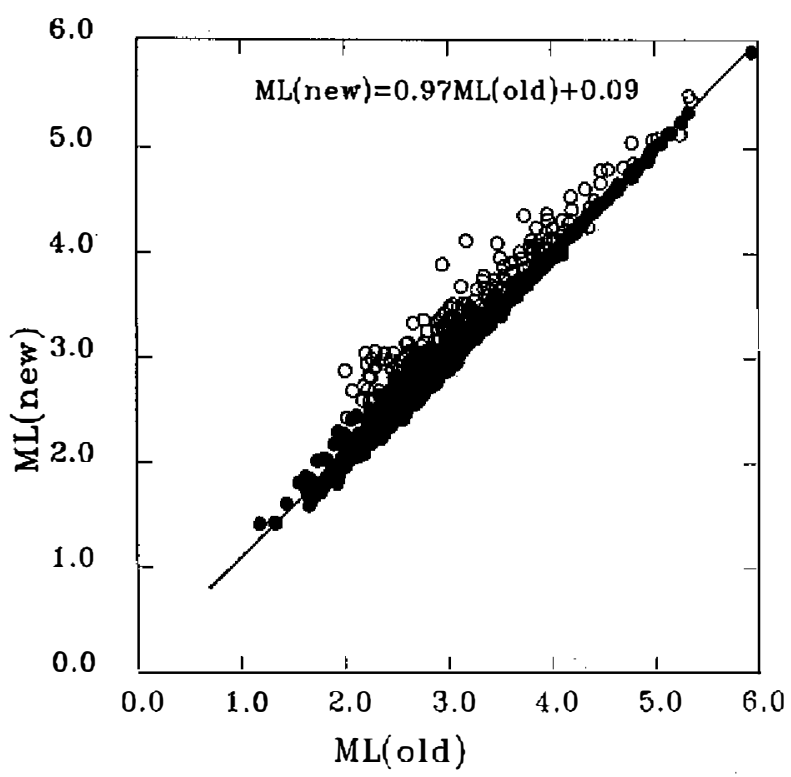

Fig. 11. The comparison of local magnitude using $\log A_{\circ}$ of this study (denoted as $M_{L}$ (new)) and Richter's $\log A_{\circ}$ (denoted as $M_{L}$ (old)) $(1935,1958)$. The open circles are the magnitude calculated from 224 earthquakes, the solid circles belong to shallow earthquakes only.

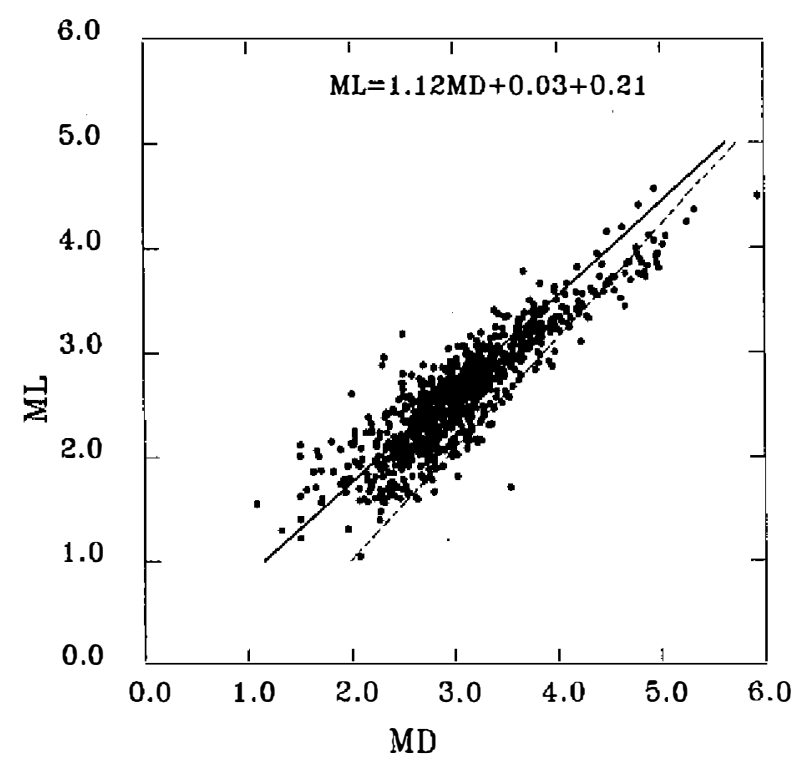

Fig. 12. The comparison of $M_{L}$ and $M_{D}$ of TTSN. A new relationship is developed written in the figure. The dashed line represents previous results of Yeh and Hsu (1985). 
The $M_{L}$ calculated by the data of accelerogram is important as the earthquake is large enough to cause the clip of the most of short-period seismograms. Because a large amount of triggered accelerograms can be used to calculate magnitude and the averaged value of magnitude will be more reasonable. In the period of Aug. 1991 to Jun. 1992, there are 28 earthquakes which triggered more than 3 strong motion accelerographs of CWBSN. Table 2 lists the parameters of all earthquakes. The strong motion data are used to simulate WoodAnderson seismograms. The $M_{L}$ magnitude (denoted as $M_{L}$ (acc)) of one event can be obtained by averaging all $M_{L}(\mathrm{acc})$ values of the event while the individual magnitude is calculated by applying the attenuation function obtained in this study. Figure 13 shows the comparison of $M_{L}$ magnitude from short-period seismogram to $M_{L}$ (acc). A bisection line can be fitted to the data with standard error of 0.2 unit of magnitude. The scattering of data points in Figure 13 is due to small number of strong motion data comparing to the short-period data. However, it suggests that a compatible magnitude can be obtained if we use strong motion data.

Table 2. Earthquake parameters.

\begin{tabular}{|c|c|c|c|c|c|c|c|c|c|c|c|}
\hline \multicolumn{3}{|c|}{ Date } & \multicolumn{3}{|c|}{ Time } & \multicolumn{4}{|c|}{ Location } & \multirow{2}{*}{$\begin{array}{l}\text { Depth } \\
\text { km }\end{array}$} & \multirow[t]{2}{*}{ ML } \\
\hline year & mo & dd & hh & min & sec & $\begin{array}{l}\text { Lat } \\
\text { Deg. }\end{array}$ & $\begin{array}{l}\text { titude } \\
\text { - Min. }\end{array}$ & $\begin{array}{l}\text { Long } \\
\text { Deg. }\end{array}$ & $\begin{array}{l}\text { gitude } \\
\text { Min }\end{array}$ & & \\
\hline 1991 & 8 & 26 & 10 & 18 & 44.74 & 24 & 2.32 & 121 & 35.22 & 22.87 & 4.84 \\
\hline 1991 & 8 & 29 & 7 & 40 & 40.39 & 24 & 3.63 & 121 & 34.52 & 19.30 & 4.50 \\
\hline 1991 & 9 & 9 & 20 & 57 & 52.21 & 22 & 43.55 & 120 & 55.44 & 1.41 & 4.77 \\
\hline 1991 & 9 & 30 & 9 & 44 & 43.68 & 22 & 36.30 & 121 & 25.60 & 18.81 & 5.94 \\
\hline 1991 & 9 & 30 & 17 & 31 & 12.94 & 23 & .46 .27 & 121 & 28.88 & 2.41 & 4.95 \\
\hline 1991 & 10 & 1 & 13 & 23 & 45.11 & 23 & 50.84 & 121 & 48.77 & 19.64 & 4.97 \\
\hline 1991 & 10 & 12 & 5 & 8 & 40.46 & 22 & 52.14 & 121 & 26.13 & 23.34 & 5.33 \\
\hline 1991 & 10 & 18 & 3 & 52 & 9.12 & 23 & 46.64 & 121 & 45.26 & 11.52 & 5.02 \\
\hline 1991 & 11 & 3 & 4 & 17 & 20.51 & 23 & 27.70 & 121 & 35.84 & 35.27 & 5.03 \\
\hline 1991 & 11 & 5 & 9 & 36 & 37.50 & 24 & 8.08 & 121 & 38.44 & 25.15 & 4.65 \\
\hline 1991 & 11 & 21 & 16 & 53 & 2.08 & 23 & 15.75 & 120 & 3.77 & 6.90 & 4.41 \\
\hline 1991 & 11 & 25 & 10 & 29 & 11.33 & 23 & 9.56 & 121 & 40.97 & 33.62 & 4.98 \\
\hline 1991 & 12 & 2 & 6 & 14 & 15.72 & 23 & 10.83 & 121 & 41.83 & 35.03 & 5.36 \\
\hline 1991 & 12 & 21 & 22 & 9 & 22.08 & 23 & 52.31 & 121 & 34.10 & 20.32 & 4.61 \\
\hline 1991 & 12 & 24 & 2 & 51 & 43.47 & 23 & 10.95 & 120 & 43.63 & 7.60 & 4.94 \\
\hline 1991 & 12 & 31 & 4 & 47 & 35.00 & 24 & 7.28 & 121 & 45.58 & 27.84 & 4.87 \\
\hline 1992 & 2 & 4 & 10 & 5 & 28.12 & 23 & 9.84 & 120 & 23.82 & 15.72 & 4.67 \\
\hline 1992 & 3 & 4 & 19 & 2 & 25.84 & 23 & 47.13 & 121 & 45.21 & 7.99 & 4.89 \\
\hline 1992 & 3 & 21 & 3 & 11 & 59.29 & 23 & 59.92 & 121 & 36.54 & 26.76 & 5.0 .5 \\
\hline 1992 & 4 & 2 & 1 & 39 & 42.75 & 24 & 6.84 & 121 & 42.45 & 24.29 & 4.98 \\
\hline 1992 & 4 & 19 & 18 & 32 & 20.75 & 23 & 50.43 & 121 & 34.47 & 8.07 & 5.57 \\
\hline 1992 & 4 & 20 & 2 & 20 & 18.44 & 23 & 48.61 & 121 & 32.97 & 25.05 & 4.93 \\
\hline 1992. & 4 & 20 & 16 & 16 & 38.80 & 24 & 27.05 & 120 & 42.86 & 8.80 & 5.19 \\
\hline 1992 & 4 & 24 & 11 & 49 & 13.33 & 23 & 48.63 & 121 & 36.58 & .77 & 5.24 \\
\hline 1992 & 5 & 1 & 4 & 31 & 8.07 & 23 & 45.53 & 121 & 31.98 & 4.06 & 4.96 \\
\hline 1992 & 5 & 28 & 23 & 19 & 35.45 & 23 & 7.93 & 121 & 21.05 & 13.68 & 5.44 \\
\hline 1992 & 5 & 31 & 13 & 16 & 47.94 & 23 & 49.56 & 121 & 33.08 & 20.83 & 4.61 \\
\hline 1992 & 6 & 8 & 4 & 58 & 7.20 & 23 & 58.44 & 121 & 38.14 & 23.08 & 4.01 \\
\hline
\end{tabular}




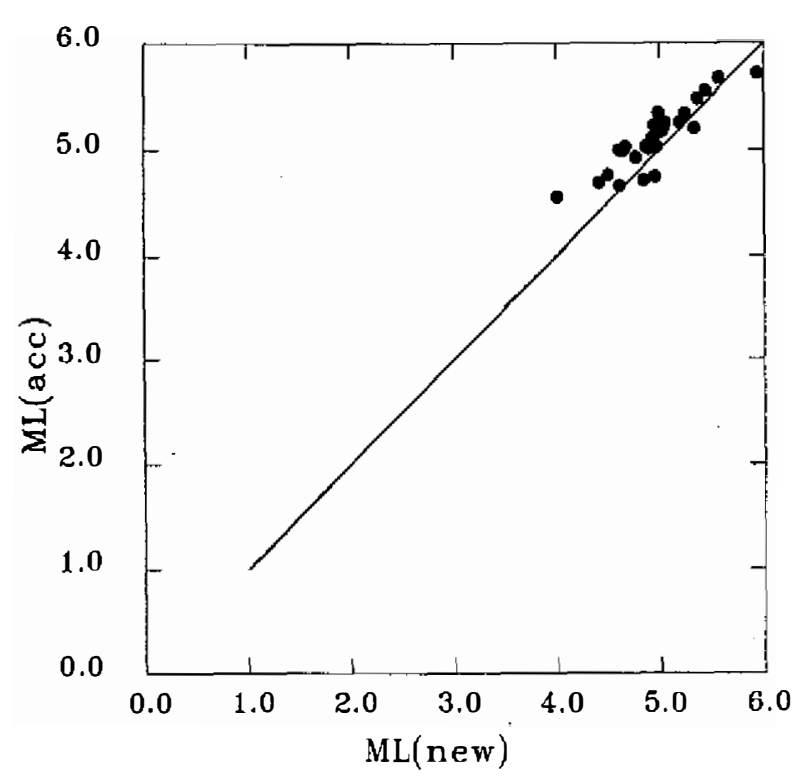

Fig. 13. $M_{L}$ vs $M_{L}$ (acc.). The data can be fitted with a line of slope one. The scatter data are due to the $M_{L}$ (acc.) is averaged by the lower number of data since the strong motion data are triggered type.

Acknowledgments This research was sponsored by the National Science Council under contract NSC81-0202-M-052-01. The author thanks his colleagues at Seismological Observation Center, CWB for routine work and is also indebted to Mr. Z.S. Chang and Ms. M. Y. Ho for their help regarding data.

\section{REFERENCES}

Bakun, W. H., and W. B. Joyner, 1984: The $M_{L}$ scale in central California, Bull. Seism. Soc. Am., 74, 1827-1844.

Bakun, W. H., S. T. Houck, and W. H. K. Lee, 1978: A direct comparison of 'synthetic' and actual Wood-Anderson seismogram, Bull. Seism. Soc. Am., 68, 1199-1202.

Bouchon, G. A., 1982: The complete synthesis of seismic crustal phases at regional distances, J. Geophys. Res., 87, 1735-1741.

Chang, L. S., and Y. T. Yeh, 1983: The $Q$ value of strong ground motions in Taiwan, Proc. Geol. Soc. China, 32, 339-353.

Campillo, M., M. Bouchon, and B. Massinon, 1984: Theoretical study of the excitation, spectral characteristics, and geometrical attenuation of regional seismic phases, Bull. Seism. Soc. Am., 74, 79-90. 
Chavez, D. E, and K. F. Priestley, 1985: $M_{L}$ observations in the Great basin and $M_{o}$ versus $M_{L}$ relationships for the 1980 Mammoth lakes, California, earthquake sequence, Bull. Seism. Soc. Am., 75, 1583-1598.

Dwyer, J. J., R. B. Hermann, and O. W. Nuttli, 1983: Spatial attenuation of the $L g$ wave in the Central United States, Bull. Seism. Soc. Am., 73, 781-796.

Hasegawa, H. S., 1983: $L g$ spectral of local earthquakes recorded by the Eastem Canada Telemetered Network and spectral analysis, Bull. Seism. Soc. Am., 73, 1041-1062.

Lee, W. H. K., R. E. Bennett, and K. I. Meagher, 1972: A method of estimating magnitude of local earthquakes from signal duration, U.S. Geol. Surv. Open File Rept., 28 pp.

Richter, C. F., 1935: An instrumental magnitude scale, Bull. Seism. Soc. Am., 25, 1-32.

Richter, C. F., 1958: Elementary Seismology, W.H. Freeman and Co., San Francisco, Califormia, $758 \mathrm{pp}$.

Shin, T. C., and R. B. Herrmann, 1987: $L g$ attenuation and source studies using 1982 Miramichi data, Bull. Seism. Soc. Am., 77, 384-397.

Shin, T. C., W. J. Su, and P. L. Leu, 1987: Coda $Q$ estimates for Taiwan area, Bull. Geophys., NCU, 27/28, 111-118.

Wang, C. Y., 1988: Calculations of $Q s$ and $Q p$ using the spectral ratio method in the Taiwan area, Proc. Geol. Soc. China, 31, 81-89.

Wang, J. H., and K. S. Liu, 1990: Azimuth variation of coda $Q$ in northern Taiwan, Geophys. Res. Lett., 17, 1315-1318.

Yeh, Y. T., and P. S. Hsu, 1985: Catalog of earthquakes in Taiwan from 1644 to 1984, Inst. Earth Sci., Acad. Sin., Taipei.

Yeh, Y. T., and G. B. Ors, and C. C. Lin, 1982: Determination of local magnitude scale for Taiwan, Bull. Inst. Earth Sci., Acad. Sin., 2, 37-48. 